\title{
Does smoking really protect from recurrent aphthous stomatitis?
}

\author{
This article was published in the following Dove Press journal: \\ Therapeutics and Clinical Risk Management \\ 19 November 2010 \\ Number of times this article has been viewed
}

\author{
Faleh A Sawair \\ Faculty of Dentistry, University \\ of Jordan, Amman, Jordan
}

Purpose: To study the effect of smoking on the prevalence of recurrent aphthous stomatitis (RAS) and to examine whether intensity and duration of smoking influence RAS lesions.

Subjects and methods: A cross-sectional survey was conducted on a random sample of 1000 students of The University of Jordan, Amman, between May and September 2008. Sociodemographic factors and details about smoking habits and RAS in last 12 months were collected.

Results: Annual prevalence (AP) of RAS was 37.1\%. Tobacco use was common among students: $30.2 \%$ were current smokers and $2.8 \%$ were exsmokers. AP was not significantly influenced by students' age, gender, marital status, college, and household income but was significantly affected by place of living $(P=0.02)$ and presence of chronic diseases $(P=0.03)$. No significant difference in AP of RAS was found between smokers and nonsmokers. Cigarette smokers who smoked heavily and for a longer period of time had significantly less AP of RAS when compared to moderate smokers and those who smoked for a shorter period of time. The protective effect of smoking was only noticed when there was heavy cigarette smoking ( $>20$ cigarettes/day) $(P=0.021)$ or smoking for long periods of time $(>5$ years $)(P=0.009)$. Nevertheless, no significant associations were found between intensity or duration of smoking and clinical severity of RAS lesions.

Conclusion: The "protective effect" of smoking on RAS was dose- and time-dependent. When lesions are present, smoking had no effect on RAS severity.

Keywords: recurrent aphthous stomatitis, smoking, prevalence

\section{Introduction}

Recurrent aphthous stomatitis (RAS) is a common oral mucosal disease that typically starts in childhood as recurrent, usually painful, small ulcers that can be single or multiple. Its prevalence rate ranges from 5\%-60\%. ${ }^{1}$ RAS is of unknown etiology; precipitated factors include stress, physical or chemical trauma, food sensitivity, and genetic predisposition. ${ }^{1,2}$ Persons with RAS may have alteration of local cellmediated immunity. ${ }^{1}$ The lesions can be associated in some individuals with systemic conditions such as Behçet's disease, gastrointestinal disease, or immune defects such as HIV/AIDS. ${ }^{3}$ The still unclear etiology has resulted in treatments that are largely empiric and aimed at symptom reduction.

Although the mechanism is not yet fully understood, investigators have noticed lower prevalence rate of RAS in smokers when compared to nonsmokers, ${ }^{4-8}$ increase in the incidence of RAS following smoking cessation, ${ }^{9-11}$ and resolution of lesions upon resumption of cigarette smoking. ${ }^{12,13}$ Although the highest incidence of RAS reported 
in the literature was found in young adults, particularly university students ${ }^{14,15}$ in whom the habit of smoking is prevalent, no studies were conducted on this group to verify this commonly held perception of smoking protection from RAS. Therefore, this investigation was conducted on a sample of university students to study the relationship between smoking and RAS among this population.

\section{Methods}

The study was conducted as face-to-face interviews with a random sample of 1000 students studying at The University of Jordan (UJ), Amman, in the period between May and September 2008. The students were given sufficient details about RAS and were shown pictures of typical cases of the condition. They were also shown pictures of recurrent herpes labialis in order to avoid mistakes between the two conditions. Students who agreed to participate were subsequently asked if they had RAS in the last 12 months. The annual prevalence (AP) of the number of students who had positive history of RAS in the last 12 months out of the surveyed sample was then calculated. The students who had a positive history of RAS were asked about the annual recurrence rate and the number of ulcers and healing period in the last episode. Data on demographic characteristics were collected for each student. Details of smoking history; method, average daily dose, and duration of the habit were taken for each student. For those who smoked cigarettes, the average number of cigarettes smoked throughout life (average of daily smoked cigarettes multiplied by duration of habits in days) was calculated. Cigarette smokers were classified into light smokers (smoking 1-10 cigarettes/day), moderate smokers (smoking 11-20 cigarettes/day), and heavy smokers (smoking $>20$ cigarettes/day). While it was simple to record the intensity and duration of cigarette smoking, difficulties were encountered in knowing the dose or duration of narghile smoking because the habit had no constant pattern.

\section{Statistical methods}

Statistical analysis was performed using SPSS for Windows release 16.0 (SPSS Inc, Chicago, IL). Frequency distributions were obtained and chi-square test, Student's $t$-test, and ANOVA test were used to compare differences between groups. Statistical significance was set at $P<0.05$.

\section{Results}

The study population consisted of 1000 students (373 males and 627 females). Their ages ranged from 17 to 29 years (mean $=20.3 \pm 1.79$ years). The AP of RAS was $37.1 \%$;
371 students had RAS episodes in the last 12 months. Of the 371 subjects, $66.8 \%$ had a positive family history of the disease. The relationship of the AP of RAS with the different sociodemographic variables is shown in Table 1.

As shown in Table 2, tobacco use was common among this group and the prevalence was significantly higher in males $\left(P<0.001, \chi^{2}\right.$ test $)$. Of the 302 smokers, $18.1 \%$ were cigarette smokers and $12.1 \%$ were narghile smokers. While cigarette smoking was prevalent among male students, narghile smoking was equally popular among female and male students.

The prevalence of RAS was not significantly affected by history of tobacco use (Table 1). Although the prevalence of RAS was highest among ex-smokers (46.4\%), the AP in non-smokers $(36.7 \%)$ was nearly equal to that in smokers (37.1\%). In addition, the method of tobacco use, cigarettes or narghile, had no significant effect on the AP of RAS.

When the group who smoked cigarettes $(n=181)$ was studied separately in terms of AP of RAS, the prevalence was significantly affected by number of smoked cigarettes each day (Table 3). The prevalence decreased significantly as number of daily smoked cigarettes increased $\left(\chi^{2}\right.$ test; $P=0.021$ ); heavy smokers had one-third the odds of RAS (odds ratio $[\mathrm{OR}]=0.33$ ) than light smokers. In addition, cigarette smokers for periods $>5$ years also had one-third the odds of RAS $(\mathrm{OR}=0.34)$ than those who smoked for $\leq 5$ years $\left(\chi^{2}\right.$ test; $P=0.009)$. When both these two factors; intensity and duration of cigarette smoking, were combined, even moderate cigarette smokers for periods more than five years and heavy cigarette smokers for periods less than five years had significantly lower risk of getting $\operatorname{RAS}\left(\chi^{2}\right.$ test; $\left.P=0.008\right)$. The maximum number of cigarettes consumed by moderate smokers in 5 years $(36,500$ cigarettes) was used as a cut-off value above which smokers were found to have significantly lesser odds $(\mathrm{OR}=0.46)$ of RAS than those who smoked below this level ( $\chi^{2}$ test; $\left.P=0.042\right)$.

However, no significant associations were found between the number of the smoked cigarettes per day or duration of the habit and the RAS severity in terms of the number of ulcers in each episode, duration of the healing period, and annual recurrence rate (Table 4). In addition, no significant associations were found between RAS severity and total number of cigarettes smoked per life.

\section{Discussion}

Recurrent aphthous stomatitis was common among the investigated population and the AP (37.1\%) was significantly higher than that $(17.9 \%)$ reported in US adult population 
Table I Demographic variables of students and its relationship with the annual prevalence of RAS

\begin{tabular}{|c|c|c|c|c|c|c|}
\hline \multirow[t]{2}{*}{ Variables } & & \multicolumn{2}{|c|}{ Total } & \multicolumn{3}{|c|}{ Annual prevalence } \\
\hline & & $\mathbf{n}$ & $\%^{a}$ & $\mathbf{n}$ & $\%^{\mathrm{a}}$ & $P$ value $^{b}$ \\
\hline \multirow[t]{2}{*}{ Gender } & Female & 627 & 62.7 & 239 & 38.1 & 0.39 \\
\hline & Male & 373 & 37.3 & 132 & 35.4 & \\
\hline \multirow[t]{2}{*}{ Address } & Amman & 797 & 79.7 & 310 & 38.9 & 0.02 \\
\hline & Other regions & 203 & 20.3 & 61 & 30 & \\
\hline \multirow[t]{2}{*}{ Marital status } & Single & 980 & 98.0 & 362 & 36.9 & 0.46 \\
\hline & Married & 20 & 2.0 & 9 & 45 & \\
\hline \multirow[t]{3}{*}{ College } & Health & 295 & 29.5 & 105 & 35.6 & 0.73 \\
\hline & Science & 395 & 39.5 & 146 & 37 & \\
\hline & Humanitarian & 310 & 31.0 & 120 & 38.7 & \\
\hline \multirow[t]{2}{*}{ Household income/month } & $<500$ JOD & 296 & 29.6 & 114 & 38.5 & 0.55 \\
\hline & $\geq 500$ JOD & 704 & 70.4 & 257 & 36.5 & \\
\hline \multirow[t]{7}{*}{ Chronic disease } & Absent & 905 & 90.5 & 326 & 36.0 & 0.03 \\
\hline & Present & 95 & 9.5 & 45 & 47.4 & \\
\hline & Anemia & 25 & 2.5 & 13 & 52 & \\
\hline & GIT disease & 7 & 0.7 & 3 & 42.9 & \\
\hline & Allergies & 38 & 3.8 & 16 & 42.1 & \\
\hline & Endocrine disorders & II & I.I & 5 & 45.5 & \\
\hline & Others & 14 & $\mathrm{I} .4$ & 8 & 57.1 & \\
\hline \multirow[t]{4}{*}{ Smoking } & No & 670 & 67.0 & 246 & 36.7 & 0.72 \\
\hline & Exsmoker & 28 & 2.8 & 13 & 46.4 & \\
\hline & Narghile smokers & 121 & 12.1 & 47 & 38.8 & \\
\hline & Cigarette smokers & 181 & 18.1 & 65 & 35.9 & \\
\hline
\end{tabular}

Notes: aRaw percentage; ' ${ }^{\circ}$ hi-square test.

Abbreviations: GIT, gastrointestinal; JOD, Jordanian Dinar (JOD I = I.4\$); n, number; RAS, recurrent aphthous stomatitis.

aged over 17 years. ${ }^{8}$ However, a high prevalence of RAS $(60 \%)$ was reported in US female student nurses. ${ }^{14}$ Although it is expected that young educated people provide rationally accurate data regarding RAS, the possibility that the recurrent oral ulcerations reported by the investigated population were caused by other factors can not be excluded. The results of this study revealed also widespread tobacco use among Jordanian university students. Nearly $30 \%$ were users of tobacco products and, even in this conservative community, the habit was becoming increasingly common among females.

Although better understanding of the relationship between smoking and RAS might be important in clarifying the still unknown etiology and pathogenesis of RAS, only a few studies ${ }^{4-13}$ were designed specifically to examine this relationship.
The results of this study showed high occurrence of RAS in both smokers and nonsmokers. RAS prevalence between smokers and nonsmokers was not significantly different. Our findings contradict previous studies that found a negative epidemiological association between tobacco use and RAS. ${ }^{4-13}$ Some of these studies were observational studies on three or four patients ${ }^{12,13}$ or recruited a small number of patients with RAS. ${ }^{6,8}$ Other studies were conducted in hospitals or university clinics with a possible selection bias. ${ }^{6,7}$ In addition, other studies that found significant relationships between smoking and RAS used only bivariate analyses..$^{5-7}$ Several variables found to be significant in bivariate analyses may turn insignificant in multivariate model. For instance, it is well-known that while RAS prevalence decreases with

Table 2 Tobacco use among a sample of 1000 male and female students studying at the University of Jordan

\begin{tabular}{|c|c|c|c|c|c|c|c|c|c|c|}
\hline & \multirow{2}{*}{\multicolumn{2}{|c|}{ Total }} & \multicolumn{8}{|c|}{ Smoking history } \\
\hline & & & \multicolumn{2}{|c|}{ Nonsmokers } & \multicolumn{2}{|c|}{ Exsmokers } & \multicolumn{2}{|c|}{$\begin{array}{l}\text { Cigarette } \\
\text { smokers }\end{array}$} & \multicolumn{2}{|c|}{$\begin{array}{l}\text { Narghile } \\
\text { smokers }\end{array}$} \\
\hline & $\mathbf{n}$ & $\%^{a}$ & $\mathbf{n}$ & $\%^{\mathrm{a}}$ & $\mathbf{n}$ & $\%^{\mathrm{a}}$ & $\mathbf{n}$ & $\%^{\mathrm{a}}$ & $\mathbf{n}$ & $\%^{\mathrm{a}}$ \\
\hline Female & 627 & 62.7 & 491 & 78.3 & 14 & 2.2 & 48 & 7.7 & 74 & 11.8 \\
\hline Male & 373 & 37.3 & 179 & 48.0 & 14 & 3.8 & 133 & 35.7 & 47 & 12.6 \\
\hline Total & 1000 & 100 & 670 & 67.0 & 28 & 2.8 & 181 & 18.1 & 121 & 12.1 \\
\hline
\end{tabular}

Note: aRaw percentage.

Abbreviation: $\mathrm{n}$, number. 
Table 3 Details of cigarette smoking habit in the current smokers $(n=18 I)$ and its relationship with the annual prevalence of RAS

\begin{tabular}{|c|c|c|c|c|c|c|c|}
\hline \multirow[t]{2}{*}{ Smoking } & \multicolumn{2}{|c|}{ Total } & \multicolumn{5}{|c|}{ Annual prevalence } \\
\hline & $\mathbf{n}$ & $\%^{\mathrm{a}}$ & $\mathbf{n}$ & $\%^{\mathrm{a}}$ & Odds ratio & $95 \% \mathrm{Cl}$ & $P$ value ${ }^{b}$ \\
\hline Amount (cigarette/day) & & & & & & & 0.021 \\
\hline Light smoker & 52 & 28.7 & 23 & 44.2 & 1.00 & & \\
\hline Moderate smoker & 86 & 47.5 & 33 & 38.4 & 0.79 & $0.39-1.58$ & \\
\hline Heavy smoker & 43 & 23.8 & 9 & 20.9 & 0.33 & $0.13-0.83$ & \\
\hline Duration (years) & & & & & & & 0.009 \\
\hline$\leq 5$ & 139 & 76.8 & 57 & 41 & 1.00 & & \\
\hline$>5$ & 42 & 23.2 & 8 & 19 & 0.34 & $0.15-0.79$ & \\
\hline Amount $\times$ duration & & & & & & & 0.008 \\
\hline Light smoker for $\leq 5$ years & 50 & 27.6 & 23 & 46 & 1.00 & & \\
\hline Light smoker for $>5$ years & 2 & 1.1 & 0 & 0 & - & - & \\
\hline Moderate smoker for $\leq 5$ years & 67 & 37 & 29 & 43.3 & 0.90 & $0.43-1.87$ & \\
\hline Moderate smoker for $>5$ years & 19 & 10.5 & 4 & 21.1 & 0.31 & $0.09-0.98$ & \\
\hline Heavy smoker for $\leq 5$ years & 22 & 12.2 & 5 & 22.7 & 0.35 & $0.11-0.99$ & \\
\hline Heavy smoker for $>5$ years & 21 & 11.6 & 4 & 19 & 0.28 & $0.08-0.94$ & \\
\hline Amount (cigarette/life) & & & & & & & 0.042 \\
\hline$\leq 36,500^{c}$ & 127 & 70.2 & 52 & 40.9 & 1.00 & & \\
\hline$>36,500$ & 54 & 29.8 & 13 & 24.1 & 0.46 & $0.22-0.94$ & \\
\hline
\end{tabular}

Notes: ${ }^{a}$ Raw percentage; ${ }^{b}$ Chi-square test; ' Maximum number of cigarettes consumed by moderate smokers in 5 years. Light smoker (those who smoke I-10 cigarettes/day); moderate smoker (those who smoke II-20 cigarettes/day); heavy smoker (those who smoke $>20$ cigarettes/day).

Abbreviations: $\mathrm{Cl}$, confidence interval; $n$, number; RAS, recurrent aphthous stomatitis.

increasing age, smoking prevalence and amount of cigarettes consumed usually increase with time. Therefore, it is possible that higher mean age of smokers compared to non-smokers was responsible for the significantly lower prevalence of RAS in smokers reported in some studies that used only bivariate analysis. In addition, increase in incidence of RAS in those who ceased smoking ${ }^{9-13}$ is not a proof that smoking is responsible since other factors could be involved such as increased stress and depression, which usually affect these subjects when they stop smoking. ${ }^{16}$

However, the results of this study did not entirely exclude a possible negative epidemiological association between smoking and RAS. Significant differences in the prevalence of RAS in the group who were cigarette smokers were related to the dose and duration of the smoking habit. The "protective effect" of tobacco on RAS was only noticed when persons were heavy smokers or smoked for longer periods of time. Of course this lower prevalence of RAS in the heavy smokers shouldn't encourage smokers who suffer from RAS to increase their consumption.

Data upon the "protective effect" of smoking on RAS are controversial particularly with respect to a possible underlying mechanism. Some researchers thought that this protective effect is related to the increased keratinization of the oral mucosa in smokers and that this keratin layer acts as a mechanical and chemical barrier against trauma or microbes. ${ }^{4,5,10}$ In contrast, some have hypothesized that nicotine may be the responsible agent for the reduction in

Table 4 Relationship between smoking and severity of RAS in students who were nonsmokers or cigarette smokers and had positive history of RAS $(n=311)$

\begin{tabular}{|c|c|c|c|c|c|c|}
\hline & $\begin{array}{l}\text { Number of ulcers/last episode } \\
\text { Mean }(95 \% \mathrm{Cl})\end{array}$ & $P$ value $^{\mathrm{a}}$ & $\begin{array}{l}\text { Healing } \\
\text { period/days }\end{array}$ & $P$ value $^{\mathrm{a}}$ & $\begin{array}{l}\text { Recurrence rate/year } \\
\text { Mean }(95 \% \mathrm{Cl})\end{array}$ & $P$ value $^{a}$ \\
\hline \multicolumn{7}{|c|}{ Number of cigarettes/day } \\
\hline $0(n=246)$ & $1.49(1.37-1.61)$ & 0.52 & $5.91(5.45-6.36)$ & 0.77 & $3.50(3.14-3.87)$ & 0.12 \\
\hline $1-10(n=23)$ & $1.39(1.18-1.61)$ & & $5.91(4.78-7.04)$ & & $4.57(3.05-6.08)$ & \\
\hline $1 \mathrm{I}-20(\mathrm{n}=33)$ & $1.36(1.10-1.63)$ & & $6.30(4.34-8.26)$ & & $2.79(1.91-3.66)$ & \\
\hline$>20(n=9)$ & I.II (0.85-1.37) & & 7.11 (4.38-9.84) & & $4.56(0.62-8.50)$ & \\
\hline \multicolumn{7}{|c|}{ Duration (year) } \\
\hline $0(n=246)$ & $1.49(\mid .37-1.6 I)$ & 0.29 & $5.91(5.45-6.36)$ & 0.70 & $3.50(3.14-3.87)$ & 0.84 \\
\hline$\leq 5(n=57)$ & $1.30(1.15-1.45)$ & & $6.19(5.01-7.38)$ & & $3.60(2.78-4.4 I)$ & \\
\hline$>5(n=8)$ & $1.62(0.86-2.39)$ & & $6.88(3.40-10.35)$ & & $4.12(1.00-8.56)$ & \\
\hline
\end{tabular}

Note: ${ }^{\text {aANOVA test. }}$

Abbreviations: $\mathrm{Cl}$, confidence interval; $\mathrm{n}$, number; RAS, recurrent aphthous stomatitis. 
RAS prevalence rate in smokers. ${ }^{8}$ Nicotine has been shown to affect the immune response in inflammatory conditions by inducing the production of adrenal steroids through the hypothalamus-pituitary-adrenal axis and reducing the production of tumor necrosis factor- $\alpha$ (TNF- $\alpha$ ) and interleukins 1 and 6 through its direct effect on macrophages. ${ }^{17}$

Some investigators support the belief that nicotine may act as protector of the oral mucosa in the patients with RAS while subjects who quit smoking often complain of RAS and resumption of smoking results in the faster resolution of RAS. ${ }^{9-11}$ In addition, those who quit smoking are less likely to develop RAS if they use nicotine replacement therapy (NRT) as compared to those who do not use NRT. ${ }^{11}$ Few investigators suggested that smokers may be less psychologically stressed than nonsmokers and that some psychological trigger might affect RAS development. ${ }^{1}$ The association found in this study between heavy cigarette smoking and less prevalence of RAS even for periods less than five years suggests that nicotine may play a role in preventing the occurrence of RAS and that this protective effect of nicotine is dose dependent. Since the amount of nicotine inhaled with tobacco smoke is quite small because most of the substance is destroyed by the heat, ${ }^{18}$ consumption of cigarettes in amounts exceeding a packet per day may result in a protective nicotine dose. Increased keratinization of the mucosa and consequently less susceptibility to ulceration could explain the finding that moderate smokers for periods more than five years had a lower risk of getting RAS; moderate smoking had no protective effect on RAS in periods less than five years. As shown in this study, smoking of around 36,500 cigarettes was needed for the formation of a protective layer of keratin.

\section{Conclusion}

The current study acknowledges a "protective effect" of smoking on RAS, but only in conditions of high level of consumption that result in enough concentration of nicotine or long period of consumption to produce a protective layer of keratin. However, no significant associations were found between intensity and duration of smoking and severity of RAS lesions.

\section{Disclosure}

The author declares no conflicts of interest in relation to this work.

\section{References}

1. Jurge S, Kuffer R, Scully C, Porter SR. Mucosal disease series. Number VI. Recurrent aphthous stomatitis. Oral Dis. 2006;12:1-21.

2. Woo SB, Sonis ST. Recurrent aphthous ulcers: a review of diagnosis and treatment. J Am Dent Assoc. 1996;127:1202-1213.

3. Vucicevic Boras V, Savage NW. Recurrent aphthous ulcerative disease: presentation and management. Aust Dent J. 2007;52:10-15.

4. Shapiro S, Olson DL, Chellemi SJ. The association between smoking and aphthous ulcers. Oral Surg Oral Med Oral Pathol. 1970;30:624-630.

5. Axéll T, Henricsson V. Association between recurrent aphthous ulcers and tobacco habits. Scand J Dent Res. 1985;93:239-242.

6. Tüzün B, Wolf R, Tüzün Y, Serdaroğlu S. Recurrent aphthous stomatitis and smoking. Int J Dermatol. 2000;39:358-360.

7. Atkin PA, Xu X, Thornhill MH. Minor recurrent aphthous stomatitis and smoking: an epidemiological study measuring plasma cotinine. Oral Dis. 2002;8:173-176.

8. Rivera-Hidalgo F, Shulman JD, Beach MM. The association of tobacco and other factors with recurrent aphthous stomatitis in an US adult population. Oral Dis. 2004;10:335-345.

9. Ussher M, West R, Steptoe A, McEwen A. Increase in common cold symptoms and mouth ulcers following smoking cessation. Tob Control. 2003;12:86-88.

10. McRobbie H, Hajek P, Gillison F. The relationship between smoking cessation and mouth ulcers. Nicotine Tob Res. 2004;6:655-659.

11. Marakoğlu K, Sezer RE, Toker HC, Marakoğlu I. The recurrent aphthous stomatitis frequency in the smoking cessation people. Clin Oral Investig. 2007;11:149-153.

12. Brookman R. Relief of canker sores on resumption of cigarette smoking. Calif Med. 1960;93:235-236.

13. Dorsey C. More observations on relief of aphthous stomatitis on resumption of cigarette smoking. A report of three cases. Calif Med. 1964;101:377-378.

14. Ship II. Epidemiologic aspects of recurrent aphthous ulcerations. Oral Surg Oral Med Oral Pathol. 1972;33:400-406.

15. Ship II. Socioeconomic status and recurrent aphthous ulcers. J Am Dent Assoc. 1966;73:120-123.

16. Kinnunen T, Doherty K, Militello FS, Garvey AJ. Depression and smoking cessation: characteristics of depressed smokers and effects of nicotine replacement. J Consult Clin Psychol. 1996;64:791-798.

17. Floto RA, Smith KG. The vagus nerve, macrophages, and nicotine. Lancet. 2003;361:1069-1070.

18. Rose JE, Behm FM, Westman EC, Coleman RE. Arterial nicotine kinetics during cigarette smoking and intravenous nicotine administration: implications for addiction. Drug Alcohol Depend. 1999;56: 99-107.
Therapeutics and Clinical Risk Management

\section{Publish your work in this journal}

Therapeutics and Clinical Risk Management is an international, peerreviewed journal of clinical therapeutics and risk management, focusing on concise rapid reporting of clinical studies in all therapeutic areas, outcomes, safety, and programs for the effective, safe, and sustained use of medicines. This journal is indexed on PubMed Central, CAS,

\section{Dovepress}

EMBase, Scopus and the Elsevier Bibliographic databases. The manuscript management system is completely online and includes a very quick and fair peer-review system, which is all easy to use. Visit http://www.dovepress.com/testimonials.php to read real quotes from published authors. 